\title{
PALM-BASED CHOCOLATE SPREAD FOR WIDE RANGE TEMPERATURE APPLICATIONS USING SUNFLOWER WAX, CARNAUBA WAX AND BEES WAX
}

\section{NORAZURA AILA MOHD HASSIM"1*; SIVARUBY KANAGARATNAM ${ }^{1}$; NUR HAQIM ISMAIL'; NOOR LIDA HABI MAT DIAN ${ }^{1}$; WAN ROSNANI AWG ISA ${ }^{1}$ and NOOR SOFFALINA SOFIAN SENG ${ }^{2}$}

\begin{abstract}
The study was conducted to produce chocolate spread (CS) with a wide range temperature applications $\left(5^{\circ} \mathrm{C}-45^{\circ} \mathrm{C}\right.$ ) by using blended base oil [50\% palm superolein (POOo) and 50\% sunflower oil (SFO)] and different types of waxes [0\%-3.5\% sunflower wax (SFW), carnauba wax (CW) and bees wax (BW)]. The waxes were added to impart solid-like property to a low saturated fatty acids oil blend in the CS. The main analysis for the oil system without wax (OSWW) was solid fat content (SFC) while the analysis for CS using these oils was hardness and spreadability. Main analyses for the oil system with wax (OSW) were SFC as well as hardness, spreadability and stability of CS containing different percentage of OSW. POOo:SFO at 50:50 ratio was chosen as OSWW as its SFC was not affected by temperature, and its CS showed good spreadability at $5^{\circ} \mathrm{C}$ which provided lower significant hardness than commercial CS at $5^{\circ} \mathrm{C}$. CS produced from OSW of 3.5\% SFW and 3.5\% CW showed promising outcome with no phase separation at $5{ }^{\circ} \mathrm{C}-40^{\circ} \mathrm{C}$ after $24 \mathrm{hr}$ of storage and good spreadability (hardness of $1636 \mathrm{~g}_{f}$ and $1492 \mathrm{~g}_{f}$ respectively) compared to commercial CS (hardness of $2105 \mathrm{~g}$ ) which showed no spreadability at $5^{\circ} \mathrm{C}$.
\end{abstract}

Keywords: bees wax, carnauba wax, chocolate spread, palm superolein, sunflower wax.

Received: 11 August 2021; Accepted: 2 November 2021; Published online: 21 December 2021.

\section{INTRODUCTION}

Chocolate spread (CS) is a type of confectionery and is loved by all walks of life especially children. It is usually spread on bread, pancakes or used as filling in bakery products. CS contains oils and fats that provide desirable physical properties such as spreadability and structural stability to it. These physical properties depend on the chemical structure of the oils and fats, especially on the fatty acid (FAC) and triacylglycerols (TAG) compositions. Traditional or common CS uses oils and fats from partial hydrogenation process to

\footnotetext{
1 Malaysian Palm Oil Board,

6 Persiaran Institusi, Bandar Baru Bangi,

43000 Kajang, Selangor, Malaysia.

Universiti Kebangsaan Malaysia, 43600 UKM Bangi, Selangor, Malaysia.

* Corresponding author email: azuraaila@mpob.gov.my
}

obtain the desirable physical properties. However, partial hydrogenation product contains trans fatty acid that is detrimental to health in which United States of America (USA) Food and Drug Administration (FDA) has banned the use of this fat (Kushairi et al., 2018). Alternatives to trans fatty acid have been sought after by manufacturers as well as researchers and some of the alternatives found are palm fractions [palm oil (PO), palm olein (POo), palm stearin (POs), as well as red POo] and butter fat or blended palm fractions with other vegetable oils (El-Hadad et al., 2011; El-Kalyoubi et al., 2011; Jeyarani et al., 2013). Some food manufacturers used special processing techniques (e.g., tailor-made fractionation) to minimise trans fatty acid (Roe et al., 2013).

CS should be stable at room temperature for at least 6-12 months (Shamsudin, 2004). CS will show phase separation/oil out (instable) at higher temperature (especially summer of 
$40^{\circ} \mathrm{C}$ and above) and solidify at low temperature (especially winter of $10^{\circ} \mathrm{C}$ and below). The oil out and solidification scenarios are common for a fourseason country. These scenarios will eventually affect the stability of the CS especially during storage and transportation as in most cases airconditioning is not provided during these two conditions. Therefore, there is a need to formulate a chocolate that is stable at a wide range of temperature $\left(5^{\circ} \mathrm{C}-45^{\circ} \mathrm{C}\right)$.

In formulating a CS of good spreadability and structurally stable at wide temperature range $\left(5^{\circ} \mathrm{C}-45^{\circ} \mathrm{C}\right)$, wax containing high percentage of wax ester might be suitable as they can act as gelling agent to the oil by trapping the oil in a three-dimensional (3D) network to mimic solid fat (Manzocco et al., 2017). For example, wax ester of sunflower wax (SFW) is 75\%-85\% (Endlein and Peleikis, 2011), carnauba wax (CW) is $96 \%-97 \%$ (Doan et al., 2017) and bees wax (BW) is $46.9 \%-82.0 \%$ (Aguilar et al., 2007). The percentage of wax ester might affect gelling process of the oil system without wax (OSWW) and consequently, affect hardness and spreadability of CS. Other wax components such as fatty acid, fatty alcohol and n-alkane are present in small amounts and will less influence the gelling process in producing CS. FDA has approved natural waxes as ingredient and additive in food (Rocha et al., 2013). Gelling of soft oil such as rice bran oil, soybean oil and rapeseed oil is common in current research (Doan et. al., 2015; Patel et al., 2014; Wolfer et al., 2018). However, gelling of POo or palm superolein (POOo) or its combination with other vegetable oils is not much studied. Saw et al. (2020) studied the gelling effect of POOo with many gellators and found that SFW oleogel with at least $1 \%$ SFW was stable for 90 days at $15^{\circ} \mathrm{C}, 20^{\circ} \mathrm{C}$ and $25^{\circ} \mathrm{C}$. There was no literature found on the stability of CS at wide range of temperature by using POOo as the OSWW. However, Patel et al. (2014) reported that shellac oleogel (with rapeseed oil) was able to substitute $27 \%$ of PO in a CS formulation which was stable after four weeks of storage at $30^{\circ} \mathrm{C}$. However, full substitution of wax oleogel having low saturated fatty acid oil was yet to be explored for CS especially for the wide temperature range application $\left(5^{\circ} \mathrm{C}-45^{\circ} \mathrm{C}\right)$. Current commercial CS is only stable at $25^{\circ} \mathrm{C}$ (room temperature). Commercial CS hardened at low temperatures $\left(5^{\circ} \mathrm{C}-10^{\circ} \mathrm{C}\right)$ and showed phase separation at high temperatures $\left(40^{\circ} \mathrm{C}-45^{\circ} \mathrm{C}\right)$. In view of this, three types of wax namely SFW, CW and BW at $0 \%-3.5 \%$ were used to structure blended oil of $50 \%$ POOo and $50 \%$ sunflower oil (SFO) to produce CS that is spreadable and stable at wide range of temperatures $\left(5^{\circ} \mathrm{C}-45^{\circ} \mathrm{C}\right)$. OSWW of low SFC was used to facilitate spreadability while addition of waxes could possibly hinder phase separation. In a nutshell, the waxes were added to impart solid-like property to a low saturated fatty acids oil blend to produce a CS with a wide temperature range $\left(5^{\circ} \mathrm{C}-45^{\circ} \mathrm{C}\right)$.

\section{MATERIALS AND METHODS}

\section{Materials}

OSWW and oil system with wax (OSW) comprising POOo (iodine value of 62), SFW, $\mathrm{CW}$ and $\mathrm{BW}$ were bought from local suppliers while SFO was bought from local supermarket. Ingredients for producing CS namely sugar, flavouring and commercial CS were bought from a local supermarket while cocoa powder, protein powder, emulsifiers and milk powder were bought from local suppliers.

\section{Experimental Design and Sample Preparation}

Oil system without wax (OSWW). POOo and SFO were blended in six ratios as shown in Table 1 and were known as OSWW. The OSWW were subjected to solid fat content (SFC) analysis. Raw ingredients according to Shamsudin et al. (2015) were used to produce CS with the OSWW with slight modification. CS was produced using method according to Shamsudin (2004) but without the aqueous phase. These CS were then stabilised at $25^{\circ} \mathrm{C}$ for $24 \mathrm{hr}$ and then stored at experimental temperatures before conducting hardness and spreadability test.

\begin{tabular}{cc}
$\begin{array}{c}\text { TABLE 1. VARIOUS BASE OIL (OSWW) RATIO OF PALM } \\
\text { SUPEROLEIN (POOo) AND SUNFLOWER OIL (SFO) }\end{array}$ \\
\hline No. & Base oil/oil system without wax (OSWW) ratio \\
(POOo:SFO)
\end{tabular}

Oil system with wax (OSW). As shown in Table 2 , three types of waxes namely SFW, CW and BW at different percentages $(0 \%-3.5 \%)$ were blended with the selected OSWW and was called OSW. This OSW was subjected to SFC analysis. Raw ingredients according to Shamsudin et al. (2015) was used to produce CS with OSW. These CS were stabilised at $25^{\circ} \mathrm{C}$ for $24 \mathrm{hr}$ and then stored at experimental temperatures for three types of analyses namely hardness, spreadability and stability (oiling out). 
TABLE 2. EXPERIMENTAL DESIGN OF OIL SYSTEM WITH WAX (OSW)

\begin{tabular}{|c|c|c|}
\hline Oil & Type of wax & Percentage of wax \\
\hline \multirow{24}{*}{ Selected oil } & \multirow[t]{8}{*}{ Sunflower wax (SFW) } & $0 \%$ \\
\hline & & $0.5 \%$ \\
\hline & & $1.0 \%$ \\
\hline & & $1.5 \%$ \\
\hline & & $2.0 \%$ \\
\hline & & $2.5 \%$ \\
\hline & & $3.0 \%$ \\
\hline & & $3.5 \%$ \\
\hline & \multirow[t]{8}{*}{ Carnauba wax (CW) } & $0 \%$ \\
\hline & & $0.5 \%$ \\
\hline & & $1.0 \%$ \\
\hline & & $1.5 \%$ \\
\hline & & $2.0 \%$ \\
\hline & & $2.5 \%$ \\
\hline & & $3.0 \%$ \\
\hline & & $3.5 \%$ \\
\hline & \multirow[t]{8}{*}{ Bees wax (BW) } & $0 \%$ \\
\hline & & $0.5 \%$ \\
\hline & & $1.0 \%$ \\
\hline & & $1.5 \%$ \\
\hline & & $2.0 \%$ \\
\hline & & $2.5 \%$ \\
\hline & & $3.0 \%$ \\
\hline & & $3.5 \%$ \\
\hline
\end{tabular}

\section{Methods}

Solid fat content (SFC). SFC of selected OSWW and OSW as shown in Tables 1 and 2 was measured according to AOCS Official Method Cd 16b-93 (AOCS, 2012) using pulsed nuclear magnetic resonance (NMS Minispec from Bruker, Germany). Samples (OSWW and OSW) were melted at $90^{\circ} \mathrm{C}$ for at least $1 \mathrm{hr}$ and filled into NMR tubes of $0.8 \mathrm{~cm}$ (diameter) and $3 \mathrm{~cm}$ (height). Samples were placed at $0^{\circ} \mathrm{C}$ for $90 \mathrm{~min}$ and the SFC were measured at $5^{\circ} \mathrm{C}, 10^{\circ} \mathrm{C}, 15^{\circ} \mathrm{C}, 20^{\circ} \mathrm{C}, 25^{\circ} \mathrm{C}, 30^{\circ} \mathrm{C}, 35^{\circ} \mathrm{C}, 37^{\circ} \mathrm{C}, 40^{\circ} \mathrm{C}$ and $45^{\circ} \mathrm{C}$. Three measurements were taken for each experimental temperature.

Fatty acid composition (FAC). FAC of the selected OSWW and OSW was analysed using gas chromatography (GC) based on fatty acid methyl esters (FAME) by weighing $0.1 \mathrm{~g}$ samples and dissolving it in $1.8 \mathrm{~mL}$ hexane. Vortex mixer was used to mix the sample's solution. Methylation process was conducted by adding $100 \mu \mathrm{L}$ of sodium methoxide solution to the samples followed by water addition. The sample's solution was leave for $1 \mathrm{hr}$ to separate. The clear supernatant was transferred to another vial added with sodium sulphate anhydrous and kept for 15 min before complete clear supernatant $(1.5 \mathrm{~mL})$ was injected into GC (Agilent Technologies, Model 7890B). Flame ionisation detector (FID) is equipped with this GC. The injector and detector temperature were set at $230^{\circ} \mathrm{C}$. The column temperature was set at $185^{\circ} \mathrm{C}$. The carrier (helium gas) having a flow rate of $1 \mathrm{~mL} / \mathrm{min}$ was used. The peaks were identified by comparing retention times with FAME standards and quantified using peak area normalisation method.

Triacylglycerol composition (TAG). TAG composition of OSWW and OSW was performed according to AOCS Official Method Ce 5b-89 (AOCS, 2012) using Ultra High-Performance Liquid Chromatography (U-HPLC) system (1290 Infinity LC System, Agilent Technologies, USA) and Agilent 1260 RI detector (Waters Corp., USA). A Cortecs UPLC C18 column (2.1 $\mathrm{mm} \times 150 \mathrm{~mm}$ length i.d; $1.6 \mu \mathrm{m}$ particle size) (Waters Corp., Milford, Massachusetts, USA) maintained at $30^{\circ} \mathrm{C}$ was used. Mobile phase of a mixture of acetone-acetonitrile at ratio 63.5:36.5 (v/v) with a flow rate of $0.25 \mathrm{~mL} / \mathrm{min}$ was used. Samples of $0.1 \mathrm{~g}$ were solubilised in $1 \mathrm{~mL}$ of acetone. HPLC grade chemicals and reagents were used. HPLC analysis was conducted in duplicate, and data was recorded as percent areas.

Hardness of chocolate spread (CS). CS of $110 \mathrm{~g}$ was placed in a $6 \mathrm{~cm}$ (diameter) $\times 6 \mathrm{~cm}$ (height) container. CS containing OSWW and OSW as shown in Tables 1 and 2, respectively were tempered at $25^{\circ} \mathrm{C}$ for $24 \mathrm{hr}$ to assist crystallisation. Tempered samples were stored at $5^{\circ} \mathrm{C}, 10^{\circ} \mathrm{C}$ and $25^{\circ} \mathrm{C}$ (for OSW) and $5^{\circ} \mathrm{C}, 10^{\circ} \mathrm{C}, 25^{\circ} \mathrm{C}, 40^{\circ} \mathrm{C}$ and $45^{\circ} \mathrm{C}$ (for OSW) for another $24 \mathrm{hr}$. Hardness of CS was measured using Texture Analyser (TA.XT Plus, Stable Micro System, England) following method from the library of texture analyser regarding CS with modification. CS was penetrated by cylinder probe $(5 \mathrm{~mm})$ with depth of $23 \mathrm{~mm}$ with rate of $1 \mathrm{~mm} / \mathrm{min}$ with trigger force of $1 \mathrm{~g}$. Three replicates were conducted for hardness.

Spreadability of chocolate spread (CS) (by observation). The observation was based on whether the CS can be spread or not. CS of $110 \mathrm{~g}$ was placed in a $6 \mathrm{~cm}$ (diameter) $\times 6 \mathrm{~cm}$ (height) container. CS containing OSWW and OSW as shown in Tables 1 and 2, respectively were tempered at $25^{\circ} \mathrm{C}$ for $24 \mathrm{hr}$ to assist crystallisation. Tempered samples were stored at $5^{\circ} \mathrm{C}$ for another $24 \mathrm{hr}$. Spreadability of the CS were observed on its ability to spread on white paper using butter knife before $30 \mathrm{~s}$. Three replicates were conducted for spreadability.

Stability test (by observation). Stability test is the oiling out test for CS. The observation was categorised into three groups which were oil out, slightly oil out and no oil out. CS containing OSW as shown in Table 2 were tempered at $25^{\circ} \mathrm{C}$ for $24 \mathrm{hr}$ to assist crystallisation. About $20 \mathrm{~g}$ of tempered samples were placed in self-standing centrifuges. 
Samples were then stored at $5^{\circ} \mathrm{C}, 10^{\circ} \mathrm{C}, 25^{\circ} \mathrm{C}, 40^{\circ} \mathrm{C}$ and $45^{\circ} \mathrm{C}$ for another $24 \mathrm{hr}$. Oiling out of the CS were observed after storage of $24 \mathrm{hr}$ at temperatures of $5^{\circ} \mathrm{C}, 10^{\circ} \mathrm{C}, 25^{\circ} \mathrm{C}, 40^{\circ} \mathrm{C}$ and $45^{\circ} \mathrm{C}$. Three replicates were conducted for stability.

Oil extraction from commercial chocolate spread (CS) sample. This analysis was to extract oil from commercial CS to further evaluate its SFC for negative control purpose. Oil from the commercial CS samples was extracted using freeze-thaw method according to El-Hadad et al. (2011) with some modifications. The samples were stored at $5^{\circ} \mathrm{C}$ for $24 \mathrm{hr}$ and were left at room temperature for $24 \mathrm{hr}$ to melt. The melted samples were filled in centrifuge tube. The samples were centrifuged at $9500 \mathrm{rpm}$ for 30 min using Thermo Scientific Megafuge 8R. Oil was then pipetted out and mixed with sodium sulphate to eliminate moisture followed by filtration before it was used for other analysis.

Statistical analysis. Results were analysed with Minitab version 16.0 (Pennsylvania, USA) using one-way analysis of variance (ANOVA). Significance differences $(\mathrm{p} \leq 0.05)$ among the samples were analysed using the Tukey's post-hoc test. All tests were carried out in triplicates.

\section{RESULTS AND DISCUSSIONS}

\section{Base Oil without Wax (OSWW)}

Solid fat content (SFC). SFC of various oil ratios of OSWW and oil extracted from commercial CS was shown in Figure 1. All OSWW except for oil extracted from commercial product were observed to have $0 \%$ SFC at experimental temperature of $15^{\circ} \mathrm{C}$ and above. Oil extracted from commercial CS has the highest SFC at $5^{\circ} \mathrm{C}$ followed by CS having OSWW of 100\% POOo: $0 \%$ SFO, $80 \%$ POOo: $20 \%$ SFO and $60 \%$ POOo:40\% SFO. The commercial CS use palm fraction in the formulation based on its label on the packaging. These might include the use of PO and POo (El-Kalyoubi et al., 2011) in its formulation as partially hydrogenated fat from liquid oil has been phased-out (Kushairi et al., 2018). The palm fraction used in the commercial CS tested might be POo as no SFC was observed at $20^{\circ} \mathrm{C}$. Gold et al. (2011) reported that $\mathrm{POo}$ has $0 \% \mathrm{SFC}$ at $20^{\circ} \mathrm{C}$. POo (IV 56.059.1 ) is rich in oleic and palmitic acid with values of $39.8 \%-43.9 \%$ and $38.2 \%-42.9 \%$, respectively (MPOB, 2017). OSWW having 100\% POOo:0\% SFO and 80\% POOo:20\% SFO showed very minor deviation of SFC at all experimental temperatures. OSWW having $50 \%$ POOo and below were observed to have SFC of $0 \%$ or near $0 \%$ at all experimental temperatures. This can be explained by its FAC and TAG composition in each OSWW. The higher the content of POOo, the higher the saturated fatty acid which can be translated into solid fat and influence SFC of the OSWW. In terms of TAG, the higher the POOo, the higher the SUS (disaturated) TAG. In addition, SSS (trisaturated) TAG was detected at $100 \%$ POOo based on TAG study.

Decreasing trend of $\mathrm{SFC}$ at $5^{\circ} \mathrm{C}$ when percentage of POOo decreased in an OSWW was expected as this scenario was also related to their TAG composition. Spreadability is a challenge for producing stable CS across a broad temperature range with high SFC at low temperatures especially at $5^{\circ} \mathrm{C}$. SFC of blends is important at different temperatures as this will influence the hardness and spreadability of the product. The authors were of the opinion that the ideal SFC for CS with OSW to be spreadable at $5^{\circ} \mathrm{C}-10^{\circ} \mathrm{C}$ is $0 \%$ or close to $0 \%$ as further addition of wax will increase its hardness. Therefore, the selection of OSWW was based on this requirement. Based on the results obtained, OSWW with 50\% POOo:50\% SFO and below are the most suitable to work with as it has $0 \%$ SFC at temperature of $5^{\circ} \mathrm{C}-45^{\circ} \mathrm{C}$. In view that maximising POOO is a priority (more cost-effective compared to $100 \%$ SFO), $50 \%$ POOo:50\%SFO was the best option for SFC justification. It was also important to note that using oil or oil blends having $0 \%$ SFC will work for spreadability only. Waxes were added to cater phase separation at high temperatures $\left(40^{\circ} \mathrm{C}-45^{\circ} \mathrm{C}\right)$.

Hardness of chocolate spread (CS). Hardness of CS produced using various ratios of OSWW and commercial CS is shown in Figure 2. It can be observed that the hardness of all CS varied at temperatures of $5^{\circ} \mathrm{C}$ and $10^{\circ} \mathrm{C}$. However, they began to plateau at $0 \%$ at $25^{\circ} \mathrm{C}$. Prasanth Kumar et al. (2016) reported that hardness of selected CS made using $80 \%$ butterfat and $20 \%$ red POo was 88 $\mathrm{g}_{\mathrm{f}}$ at $23^{\circ} \mathrm{C}$. In this study, the hardness of CS using the OSWW was lower than the study by Prasanth Kumar et al. (2016) at $23^{\circ} \mathrm{C}$. CS containing OSWW of $100 \%$ POOo:0\%SFO and $80 \%$ POOo:0\% SFO showed the highest hardness of $6717 \mathrm{~g}_{\mathrm{f}}$ and $3386 \mathrm{~g}_{\mathrm{f}^{\prime}}$ respectively, followed by commercial product with hardness of $2105 \mathrm{~g}_{\mathrm{f}}$ at $5^{\circ} \mathrm{C}$. According to Prasanth Kumar et al. (2016), in general, higher SFC resulted to higher product's hardness. The hardness of CS at $5^{\circ} \mathrm{C}$ with $50 \%$ POOo:50\% SFO (1041 $\left.\mathrm{g}_{\mathrm{f}}\right)$ was well below the hardness of commercial product $\left(2105 \mathrm{~g}_{\mathrm{f}}\right)$ and therefore, was able to be spread at $5^{\circ} \mathrm{C}$.

Spreadability of chocolate spread (CS). Spreadability articulates acceptance of customers in CS and refers to ease of spreading of the CS and can be expressed in terms of hardness (firmness) (Aydin and Özdemir, 2017). All CS produced using various ratios of OSWW were spreadable at $5^{\circ} \mathrm{C}$ except for those containing 100\% POOo:0\% SFO, $80 \%$ 
POOo:20\% SFO and commercial product. Commercial product which was not able to spread at $5^{\circ} \mathrm{C}$ was used as negative control as it uses conventional oils and fats to structure the CS. 100\% POOo:0\% SFO contains 50.92\% SUS TAG and $0.17 \%$ SSS TAG while $80 \%$ POOo: $20 \%$ SFO contains $38.38 \%$ SUS TAG and 0\% SSS TAG which can be translated into solid fat. 50\% POOo:50\% contains only $27.59 \%$ SUS TAG and 0\% SSS TAG. Overall, 50\% POOo:50\% SFO contains 34.82\% UUU TAG with $37.59 \%$ SUU TAG which make up to $72.41 \%$ of the total TAG. No literature review was found for spreadability of $\mathrm{CS}$ at $5^{\circ} \mathrm{C}$. However, a study by
Samsudin (2006) reported that palm-based low-fat CS at $10^{\circ} \mathrm{C}$ and $20^{\circ} \mathrm{C}$ had spreadability below 90 $\mathrm{g}_{\mathrm{f}}$ and $30 \mathrm{~g}_{\mathrm{f}}$, respectively at one week of storage. Although the spreadability of CS using OSWW was determined by visual observation, the findings can be correlated with hardness values shown in Figure 2. When hardness increase, spreadability will decrease (Aydın and Özdemir, 2017; Mohd Razalli et al., 2016). As further addition of waxes is predicted to increase hardness of CS, CS with OSWW that can spread at $5^{\circ} \mathrm{C}$ is crucial for selection. In view of this, OSWW of $50 \%$ POOo:50\% SFO that has been preselected based on SFC profile was still valid.

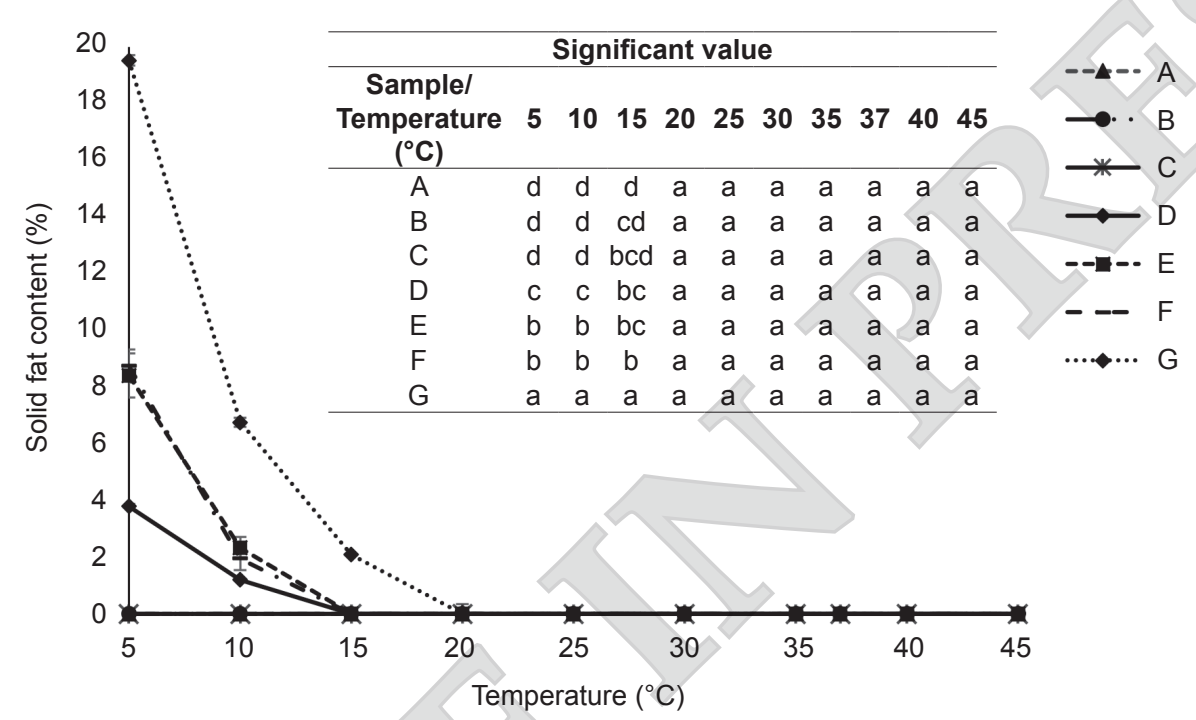

Note: Different small letters within each column in the table are significantly different $(p<0.05)$. A - 0\% POOo: 100\% SFO; B - 40\% POOo: 60\% SFO; C - 50\% POOo: $50 \%$ SFO; D - $60 \%$ POOo: 40\% SFO; E - $80 \%$ POOo: 20\% SFO; F -100\% POOo: 0\% SFO; G - Oil extracted from commercial product.

Figure 1. Solid fat content (SFC) of various oil ratios of palm superolein (POOo) and sunflower oil (SFO) as well as extracted oil from commercial chocolate spread (CS).

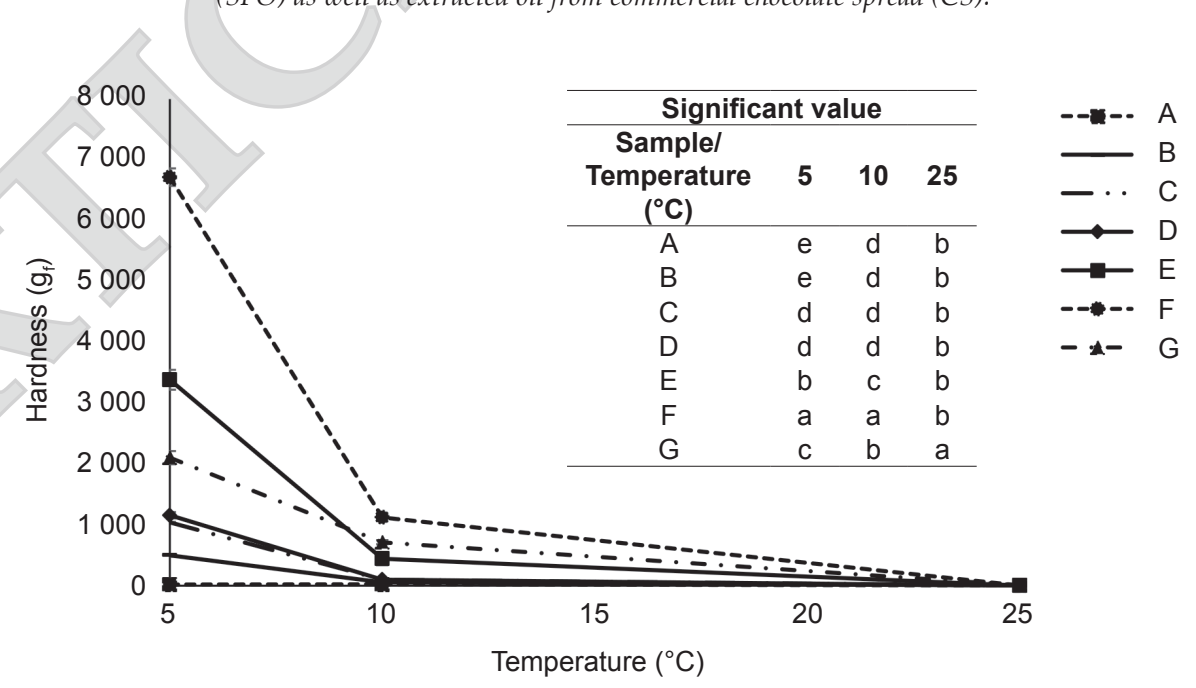

Note: Different small letters within each column in the table are significantly different $(\mathrm{p}<0.05)$. A - 0\% POOo: 100\% SFO; B - 40\% POOo: $60 \%$ SFO; C - 50\% POOo: $50 \%$ SFO; D - $60 \%$ POOo: 40\% SFO; E - 80\% POOo: 20\% SFO; F - 100\% POOo: 0\% SFO; G - Oil extracted from commercial product.

Figure 2. Hardness of chocolate spread (CS) from various ratios of base oil (OSWW) from palm superolein (POOo) and sunflower oil (SFO) as well as commercial CS. 


\section{Oil System with Waxes (OSW)}

Solid fat content (SFC). SFC of OSW with different types and percentages of waxes at experimental temperatures are shown in Figures $3 a$ (SFW), $3 b$ $(\mathrm{CW})$ and $3 c(\mathrm{BW})$. SFC of OSW with SFW (all percentages) predominantly recorded the lowest SFC compared to CW and BW. However, the SFC remains practically linear and constant trend with very slight variation across the experimental temperature used in the study $\left(5^{\circ} \mathrm{C}-45^{\circ} \mathrm{C}\right)$. This trend indicated that the OSW with SFW system did not much affected by temperature. It was expected that SFC of OSW with 3.5\% SFW will be higher than other experimental percentages of SFW due to its higher percentage of wax. However, the increment was minor and the SFC value was below 3.5\%. Notwithstanding this, OSW with 3.5\% SFW has quite similar value compared to OSW with 3.0\% SFW. A study by Yılmaz and Öğütcü (2013) revealed that an OSW with 5\% SFW and hazelnut oil had SFC of $3.64 \%$ at $20^{\circ} \mathrm{C}$ which was comparable to this study as they used higher percentage of SFW.

SFC of OSW containing CW (Figure 3b) showed a linear and constant trend at experimental temperature of $15^{\circ} \mathrm{C}-40^{\circ} \mathrm{C}$. This was aligned with the findings by Kim et al. (2017) when they found that $\mathrm{CW}$ in carnauba oil system had constant SFC for temperature of $20^{\circ} \mathrm{C}-50^{\circ} \mathrm{C}$. However, temperature of below $20^{\circ} \mathrm{C}$ was not conducted in this study. Similar to OSW with SFW, OSW with $\mathrm{CW}$ also demonstrated that 3.5\% CW as having the highest SFC at all experimental temperatures. Yi et al. (2017) discovered that SFC in a fat system containing $\mathrm{CW}$ and $\mathrm{BW}$ increased with increasing concentration of waxes. This was also supported by Kim et al. (2017), who found that lesser percentage of wax in an OSW provided lesser SFC. The SFC showed inclination at temperatures of $5^{\circ} \mathrm{C}$ and $10^{\circ} \mathrm{C}$ for all OSW containing CW. However, the SFC was still below $7 \%$.

The SFC of OSW with BW showed a declining trend at experimental temperature of $5^{\circ} \mathrm{C}-45^{\circ} \mathrm{C}$. The SFC of OSW containing 3.5\% BW was below $6 \%$ at $5^{\circ} \mathrm{C}$. At $45^{\circ} \mathrm{C}$, there was no crystalline phase as it was fully melted (Jung et al., 2020). It can be deduced that the SFC of OSW with BW was strongly temperaturedependent. This was in line with the finding by Yi et al. (2017), who reported that OSW with BW showed a decreasing $\mathrm{SFC}$ trend from $10^{\circ} \mathrm{C}-60^{\circ} \mathrm{C}$. This can be explained by low melting point of $\mathrm{BW}\left(35^{\circ} \mathrm{C}-41^{\circ} \mathrm{C}\right)$ compared to high melting point of $\mathrm{CW}\left(67^{\circ} \mathrm{C}-73^{\circ} \mathrm{C}\right)$ (Yi et al., 2017). OSW with 3.5\% BW exhibited the highest SFC, similar to OSW with SFW and CW. However, many SFC point for OSW 3.5\% BW were very close to OSW $3.0 \%$ BW.

It was observed that the three types of OSW (SFW, CW and BW) at 3.5\% showed different SFC trend. This might be due to different chemical composition of wax with the most consistent (less variation) SFC for all experimental temperatures being OSW with SFW while the most inconsistent (large variation) SFC for all experimental temperatures was BW. The addition of SFW, $\mathrm{CW}$ and $\mathrm{BW}$ at the maximum of $3.5 \%$ did not considerably increase the SFC (Figure 3) as they mainly consisted of wax ester (Doan et al., 2018). In fact, SFC of oil extracted from commercial product had higher value at $5^{\circ} \mathrm{C}$ and $10^{\circ} \mathrm{C}$ (Figure 1). The SFC of all 3.5\% OSW was expected as waxes do not interfere in the saturation level of OSWW in which their TAG/ FAC levels did not change much (Marangoni and Garti, 2011). These waxes do contain trace or small amounts of fatty acid, fatty alcohol and n-alkane (Aguilar et al., 2007; Doan et al., 2018). Therefore, when waxes were added to the selected base oil, slight increases of SFC that reflected saturated fatty acid were observed (Mert and Demirkesen, 2016). OSW experienced similar steps of nucleation, crystal growth, aggregation and network formation as conventional oils and fats. However, their crystals formation is different in type and morphology, they have lower aggregation within the crystal formed and they have the tendency for unidirectional growth. This translated into high oil binding capacity network formation for a much lower crystal (Patel and Dewettinck, 2016). Oil trapping of OSW in 3D network linkages can be seen effectively through hardness, spreadability and oil stability of the end product which is the CS. In our study, it was found that all of the experimental OSW had low SFC between $35^{\circ} \mathrm{C}-45^{\circ} \mathrm{C}$ (especially OSW with BW) indicating low waxy taste which was common for OSW that had high melting properties (Patel et al., 2014; 2013).

Hardness of chocolate spread (CS). Hardness of CS made with different types and percentages of waxes at experimental temperatures are shown in Figures $4 a(\mathrm{SFW}), 4 b(\mathrm{CW})$ and $4 c(\mathrm{BW})$, respectively. In general, hardness of $\mathrm{CS}$ at $35^{\circ} \mathrm{C}-45^{\circ} \mathrm{C}$ with OSW of SFW, CW and BW at all percentages was near to $0 \mathrm{~g}_{\mathrm{f}}$. Their hardness increased at $5^{\circ} \mathrm{C}$ but dropped significantly at $10^{\circ} \mathrm{C}$. It was stated by Daniel and Marangoni (2012) that below the melting point of OSW, solubility of the system decreases, phase separation (microscopic) transpires, and nucleation occurs upon further supercooling. This might increase hardness of CS at low temperatures. In general, at $5{ }^{\circ} \mathrm{C}$, all CS containing $3.0 \%$ and $3.5 \% \mathrm{SFW}$, $\mathrm{CW}$ and BW showed the highest hardness among their own OSW system with CS containing 3.0\% SFW displayed the highest hardness $\left(1653 \mathrm{~g}_{\mathrm{f}}\right)$ among all, while 3.5\% SFW has hardness of $1636 \mathrm{~g}_{\mathrm{f}}$ which was statistically similar to $3.0 \%$ SFW. However, this hardness was lower than the hardness of commercial $\mathrm{CS}$ at $5^{\circ} \mathrm{C}$ which was $2105 \mathrm{~g}_{\text {. }}$. 
At $5^{\circ} \mathrm{C}$ and $10^{\circ} \mathrm{C}$, hardness of CS containing SFW and CW increased with increasing levels of wax added. However, hardness of CS containing $\mathrm{BW}$ at all levels/percentages did not vary much at $5^{\circ} \mathrm{C}$, but did vary in small percentages at $10^{\circ} \mathrm{C}$. This was aligned with the finding by Lim et al. (2017) that CW in canola oil system was harder than BW in canola oil system. These figures concluded that CS with SFW displayed the largest gap in terms of hardness compared to CS without the addition of any waxes. Although SFC of OSW with SFW did not vary much with temperature, the hardness of CS produced with this OSW did affect by temperature variation especially below $25^{\circ} \mathrm{C}$. OSW precipitate upon cooling resulted to the formation of solid nuclei while liquefy during heating (Doan et al., 2018). This resulted to strong interactions of crystal as well as supramolecular entities development that trap liquid oil in 3D network when onset of crystal growth occurs (Yuping et al., 2005). This scenario can also be related to study by Doan et al. (2016) who found that beeswax oleogel at $5^{\circ} \mathrm{C}$ has stronger gel strength than $20^{\circ} \mathrm{C}$. This hardness can be observed through spreadability and stability (oiling out) of the CS. (a)

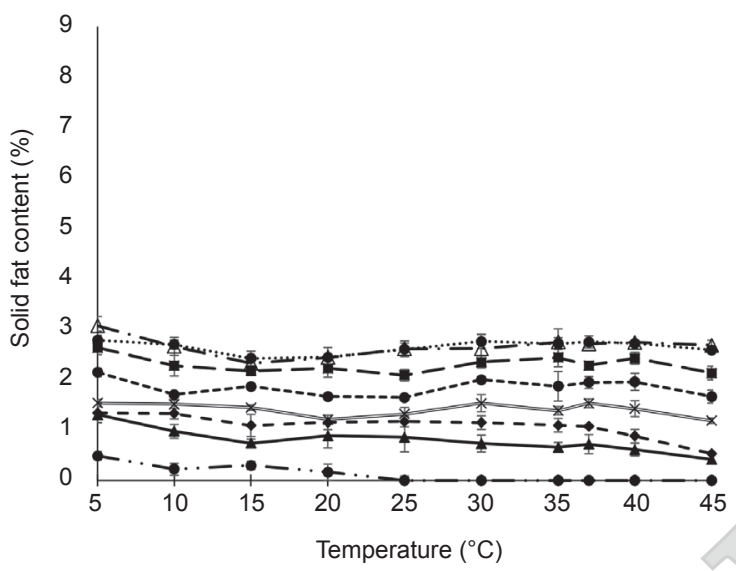

(b)

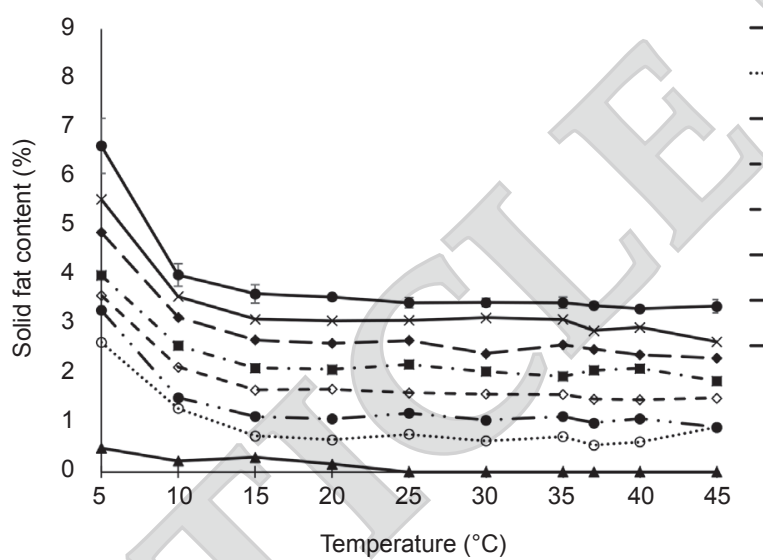

(c)

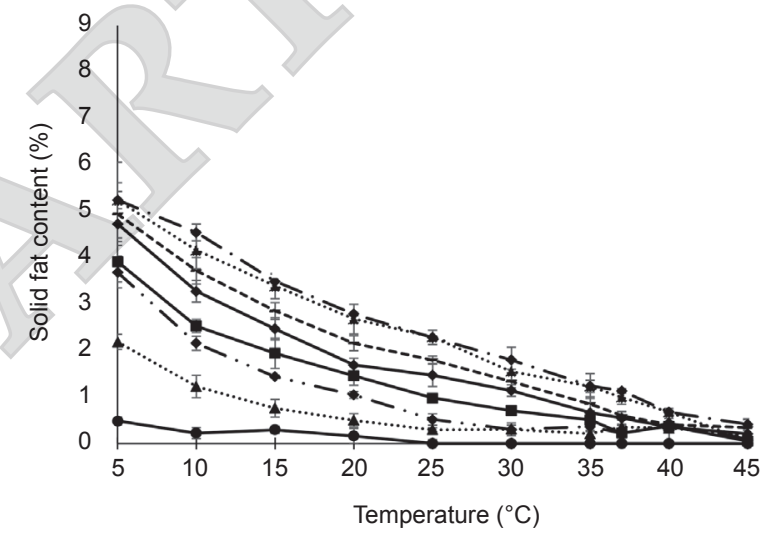

$\rightarrow$ SFW $0 \%$

$\rightarrow$ SFW $0.5 \%$

- - SFW $1.0 \%$

$\leftarrow$ SFW $1.5 \%$

$\rightarrow \rightarrow$ SFW $2.0 \%$

$\rightarrow-\mathrm{SFW} 2.5 \%$

•... SFW $3.0 \%$

$\triangle$ - - SFW $3.5 \%$
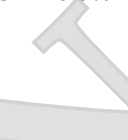

Significant value

Sample/

$\begin{array}{lllllllllll}\text { Temperature } & 5 & 10 & 15 & 20 & 25 & 30 & 35 & 37 & 40 & 45\end{array}$ $\left({ }^{\circ} \mathrm{C}\right)$

SFW 0\% $\quad$ d

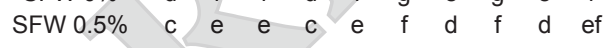

SFW $1.0 \%$ c $d$ d $c$ de $e$ c c e e d e

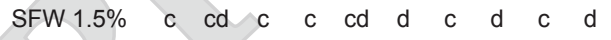

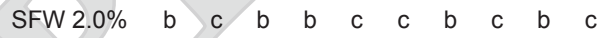

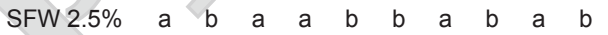

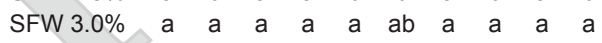

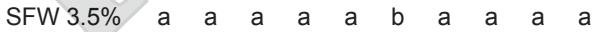

$2 \%$

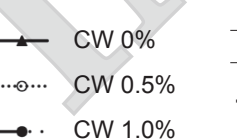

.. CW $1.0 \%$

$\rightarrow-\mathrm{CW} 1.5 \%$

- $\quad$ CW $2.0 \%$

$\rightarrow-\mathrm{CW} 2.5 \%$

CW $3.0 \%$

CW $3.5 \%$

Sample/ Significant value

$\begin{array}{lllllllllll}\text { Temperature } & 5 & 10 & 15 & 20 & 25 & 30 & 35 & 37 & 40 & 45\end{array}$ $\left({ }^{\circ} \mathrm{C}\right)$

$\begin{array}{lllllllllll}\text { CW } 0 \% & f & e & g & h & f & f & f & h & e & b\end{array}$

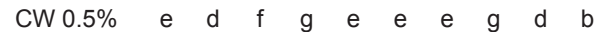

CW $1.0 \%$ de $d$ f $f$ de $d$ d $f$ f $c$

CW $1.5 \%$ cde $c$ e

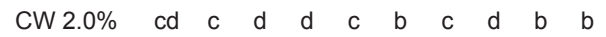

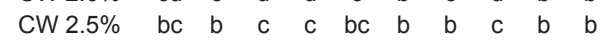

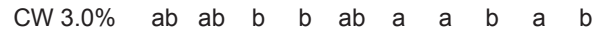

CW $3.5 \%$ a

Note: Different small letters within each column in the table are significantly different $(\mathrm{p}<0.05)$.

Figure 3. Solid fat content (SFC) of oil system with wax (OSW) containing $0 \%, 0.5 \%, 1.0 \%, 1.5 \%, 2.0 \%, 2.5 \%, 3.0 \%$ and $3.5 \%$ (a) sunflower wax (SFW) (b) carnauba wax (CW), and (c) bees wax (BW). 
(a)

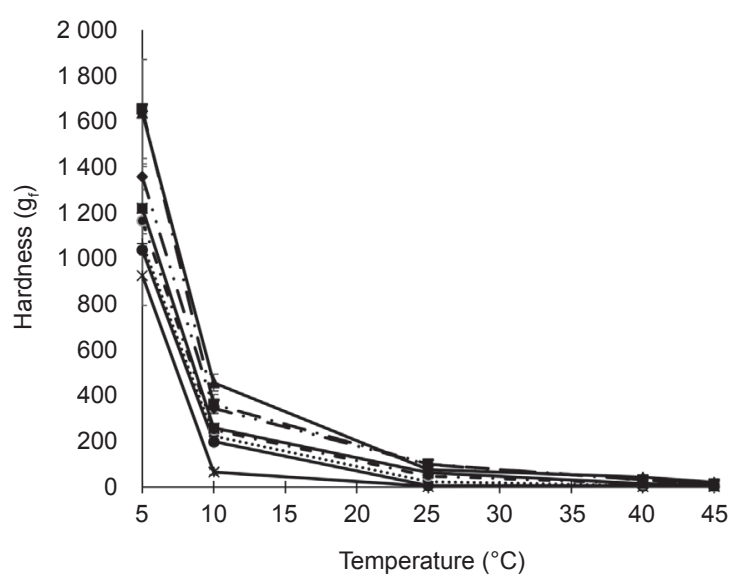

(b)

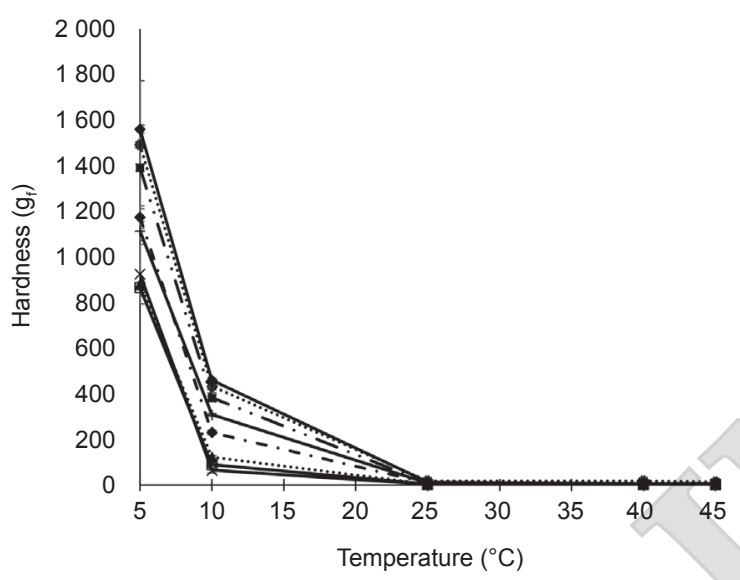

(c)

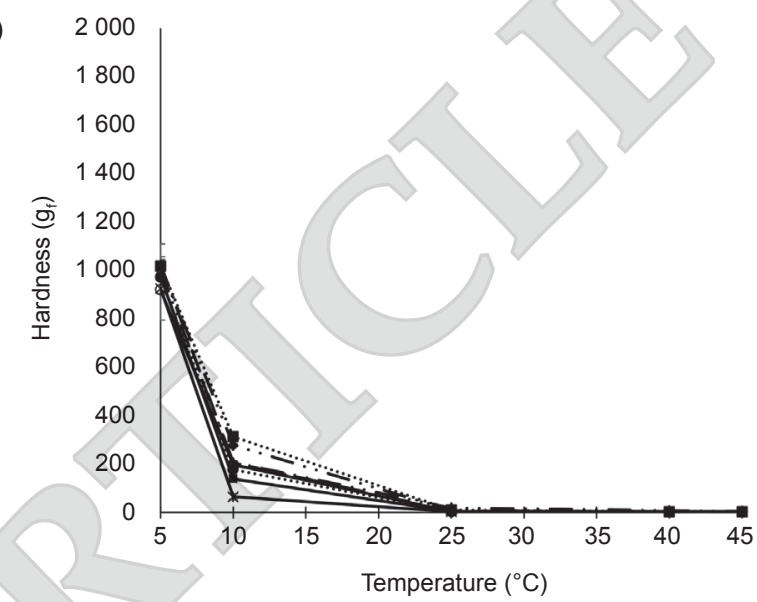

* SFW $0 \%$

$\longrightarrow$ SFW $0.5 \%$

........ SFW $1.0 \%$

- •- SFW $1.5 \%$

$\rightarrow$ SFW $2.0 \%$

$\rightarrow$ SFW $2.5 \%$

$\rightarrow$ SFW $3.0 \%$

$\longrightarrow$ SFW $3.5 \%$ $\rightarrow \quad$ CW $0 \%$

$\longrightarrow$ CW $0.5 \%$

......... CW $1.0 \%$

- CW $1.5 \%$

$\longrightarrow \quad$ CW $2.0 \%$

$\rightarrow \quad \mathrm{CW} 2.5 \%$

$\rightarrow \quad$ CW $3.0 \%$

..... CW $3.5 \%$
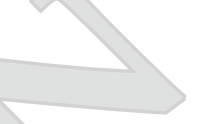

\begin{tabular}{ccccccc}
\hline \multicolumn{7}{c}{ Significant value } \\
\hline $\begin{array}{c}\text { Sample/ } \\
\text { Temperature } \\
\left({ }^{\circ} \mathrm{C}\right)\end{array}$ & $\mathbf{5}$ & $\mathbf{1 0}$ & $\mathbf{2 5}$ & $\mathbf{4 0}$ & $\mathbf{4 5}$ \\
\hline SFW 0\% & c & d & e & d & c \\
SFW 0.5\% & bc & c & e & d & c \\
SFW 1.0\% & bc & c & d & d & c \\
SFW 1.5\% & bc & c & c & c & c \\
SFW 2.0\% & bc & c & bc & c & c \\
SFW 2.5\% & ab & b & a & b & b \\
SFW 3.0\% & a & b & a & b & b \\
SFW 3.5\% & a & a & b & a & a \\
\hline
\end{tabular}

\begin{tabular}{ccccccc}
\hline \multicolumn{7}{c}{ Significant value } \\
\hline $\begin{array}{c}\text { Sample/ } \\
\text { Temperature } \\
\left({ }^{\circ} \text { C) }\right.\end{array}$ & $\mathbf{5}$ & $\mathbf{1 0}$ & $\mathbf{2 5}$ & $\mathbf{4 0}$ & $\mathbf{4 5}$ \\
$\mathrm{CW} 0 \%$ & d & d & d & c & d \\
CW $0.5 \%$ & d & d & d & c & d \\
CW $1.0 \%$ & d & d & d & c & d \\
CW $1.5 \%$ & bcd & bcd & c & c & cd \\
CW $2.0 \%$ & cd & cd & c & c & c \\
CW $2.5 \%$ & abc & abc & c & bc & c \\
CW $3.0 \%$ & a & a & b & b & b \\
CW $3.5 \%$ & ab & ab & a & a & a \\
\hline
\end{tabular}

Note: Different small letters within each column in the table are significantly different $(\mathrm{p}<0.05)$.

Figure 4. Hardness of chocolate spread (CS) with oil system containing 0\%, 0.5\%, 1.0\%, 1.5\%, 2.0\%, 2.5\%, 3.0\% and 3.5\% (a) sunflower wax (SFW) (b) carnauba wax (CW) and (c) bees wax (BW) at different temperatures.

Spreadability of chocolate spread (CS). Spreadability was only conducted at $5^{\circ} \mathrm{C}$ as all CS were spreadable at other experimental temperatures $\left(10^{\circ} \mathrm{C}, 25^{\circ} \mathrm{C}, 40^{\circ} \mathrm{C}\right.$ and $\left.45^{\circ} \mathrm{C}\right)$. It was observed that all CS were spreadable after $24 \mathrm{hr}$ of storage at $5^{\circ} \mathrm{C}$. This scenario indicated that the hardest CS (OSW of $3.0 \%$ and $3.5 \% \mathrm{SFW}$ ) with hardness value of $1653 \mathrm{~g}_{\mathrm{f}}$ and $1636 \mathrm{~g}_{\mathrm{f}}$ were still spreadable at $5^{\circ} \mathrm{C}$ after $24 \mathrm{hr}$ of storage. However, commercial CS with hardness of $2104 \mathrm{~g}_{\mathrm{f}}$ was not spreadable at $5^{\circ} \mathrm{C}$. In this case, not spreadable referred to the inability of the butter knife to scoop the CS from the bottle. This might relate to the choice of fat that was used in the commercial CS as it comprised conventional oils and fats. Although 
CS having 3.0\% and 3.5\% SFW was the hardest at $5^{\circ} \mathrm{C}$ after $24 \mathrm{hr}$ of storage, it has less than $3.5 \%$ SFC at similar temperature. Our earlier study in Figure 1 revealed that this commercial CS had $19 \%$ SFC at $5^{\circ} \mathrm{C}$. In this study, the wax trapped the oil in a $3 \mathrm{D}$ network without altering its chemical composition. Such network made spreadability possible at lower temperatures.

Stability of chocolate spread (CS). CS containing OSW of $0.5 \%-1.0 \%$ SFW has started to oil out at $25^{\circ} \mathrm{C}$ while that with $1.5 \%-3.0 \%$ SFW started to oil out at $40^{\circ} \mathrm{C}$ after $24 \mathrm{hr}$ of storage. The oiling out of CS with $3.0 \% \mathrm{SFW}$ at $40^{\circ} \mathrm{C}$ and $45^{\circ} \mathrm{C}$ after $24 \mathrm{hr}$ of storage was in small quantity. Oiling out is also known as phase separation or oil syneresis (Daniel and Marangoni, 2012). No oiling out was observed for CS containing $3.5 \% \mathrm{SFW}$ at $40^{\circ} \mathrm{C}$ after $24 \mathrm{hr}$ of storage. Therefore, CS containing 3.5\% SFW was stable at wide range of temperatures $\left(5^{\circ} \mathrm{C}-40^{\circ} \mathrm{C}\right)$ up to $24 \mathrm{hr}$ of storage. However, this CS started to oil out at $45^{\circ} \mathrm{C}$ after $24 \mathrm{hr}$ of storage. OSW and other types of oleogels have the ability to thicken food products and can be referred as oil migration inhibitors with the rationale that oil phase's thickening will restrict its movement through food matrix because of escalation of viscosity value (Daniel and Marangoni, 2012; Puscas, et al., 2020; Wendt et al., 2017). This was the result of droplet coalescence (Mwangi et al., 2016). Hwang et al. (2015) reported that SFW provided the most promising results in terms of gelling due to its high percentage and long chain ester wax. In their study, SFW was able to form gel with soybean oil at low concentration $(0.5 \%)$ and at low cooling rate. Endlein and Peleikis (2011) stated that SFW has 75\%-85\% wax ester in it.

CS containing $0.5 \% \mathrm{CW}$, started to oil out at $25^{\circ} \mathrm{C}$. However, with more levels of CW $(1.0 \%$ $3.0 \%$ ) added, oiling out scenario was only observed at $40^{\circ} \mathrm{C}$ and $45^{\circ} \mathrm{C}$. Higher levels of CW $(3.5 \%)$ shifted the oiling out scenario (slight oiling out) to $45^{\circ} \mathrm{C}$ after $24 \mathrm{hr}$ of storage. At $3.0 \% \mathrm{CW}$, oiling out has started at $40^{\circ} \mathrm{C}$ but the amount is small. Doan et al. (2017) stated that CW has wax ester of $96 \%$ $97 \%$ in which high content of wax ester produced strong gelling properties that can affect stability of its end product. According to Doan et al. (2016), BW crystallised earlier than PO due to its higher melting point compared to $\mathrm{PO}$ as crystallisation was referred as lowering the temperature from high to low. Therefore, it can be referenced that CW crystallised earlier than OSWW. As there is difference in waxes crystal microstructure and OSWW fatty acid organisation, the waxes' crystal will be the initial template for crystallisation (Doan et al., 2016).

CS with OSW of $0.5 \%-2.0 \% \mathrm{BW}$ oiled out even at $25^{\circ} \mathrm{C}$. CS containing $2.5 \%-3.5 \% \mathrm{BW}$ started to oil out at $40^{\circ} \mathrm{C}$. Aguilar et al. (2007) stated that BW has wax ester of $46.9 \%-82.9 \%$. The BW used for this study might have wax ester lesser than SFW and CW as it was not stable at $40^{\circ} \mathrm{C}$ and $45^{\circ} \mathrm{C}$.

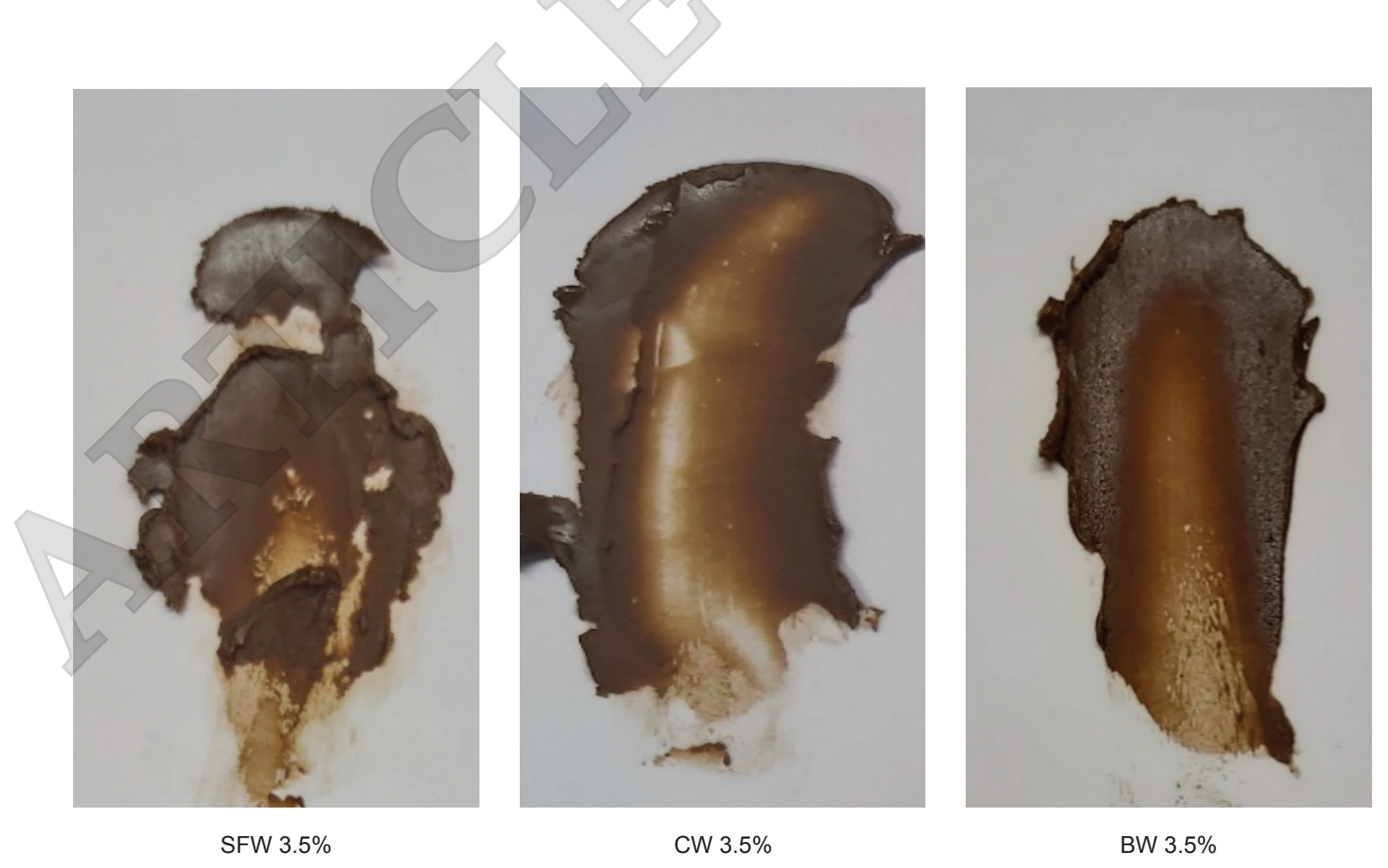

Figure 5. Examples of spreadability of chocolate spread (CS) at 3.5\% sunflower wax (SFW), carnauba wax (CW) and beeswax (BW) after $24 \mathrm{hr}$ of storage at $5^{\circ} \mathrm{C}$. 


\section{CONCLUSION}

In order to produce CS that can be spreadable at low temperatures $\left(5^{\circ} \mathrm{C}-10^{\circ} \mathrm{C}\right)$ and hinder phase separation at high temperatures $\left(40^{\circ} \mathrm{C}-45^{\circ} \mathrm{C}\right)$, waxes were added to a low saturated fatty acids oil blend. The waxes were added to impart solid-like property. Oil blend containing 50\% POOo:50\% SFO was selected as the OSWW because this oil blend showed $0 \% \mathrm{SFC}$ at temperature range of $5^{\circ}-45^{\circ} \mathrm{C}$. Notwithstanding this, CS from this oil blend was also spreadable at $5^{\circ} \mathrm{C}$ and has hardness value of $925 \mathrm{~g}_{\mathrm{f}}$, well below the commercial CS (2105 $\left.\mathrm{g}_{\mathrm{f}}\right)$. CS produced with OSWW (50\% POOo:50\% SFO) with $3.5 \%$ SFW and 3.5\% CW have good spreadability at $5^{\circ} \mathrm{C}$. These CS had hardness value of $1636 \mathrm{~g}_{\mathrm{f}}$ and 1492 $\mathrm{g}_{\mathrm{f}}$ respectively, which were well below the hardness of commercial product. In addition, these CS showed no oiling out at $40^{\circ} \mathrm{C}$ after $24 \mathrm{hr}$ of storage.

\section{ACKNOWLEDGEMENT}

The authors would like to thank the DirectorGeneral of MPOB for his permission to publish the article.

\section{REFERENCES}

Aguilar, F; Autrup, H; Barlow, S; Castle, L; Crebelli, R; Engel, K; Gontard, N; Gott, D; Grilli, S; Gürtler, R; Larsen, C; Leclercq, C; Leblanc, J; Malcata, F X; Mennes, W; Milana, M R; Pratt, I; Rietjens, I; Tobback, P and Toldrá, F (2007). Bees wax (E901) as a glazing agent and as carrier for flavours. Scientific opinion of the panel on food additives, flavourings, processing aids and materials in contact with food (AFC). EFSA J., 615: 1-28.

Akoh, C C and Min, D B (2008). Food lipids: Chemistry, Nutrition and Biotechnology. Third edition. CRC Press, Boca Raton, USA.

AOCS (2012). Official Methods and Recommended Practices of the AOCS. Vol. 6. Champaign.

Aydın, S and Özdemir, Y (2017). Development and characterization of carob flour based functional spread for increasing use as nutritious snack for children. J. Food Qual., 2017. DOI: $10.1155 / 2017 / 5028150$.

Daniel, C E and Marangoni, A G (2012). Organogels: An alternative edible oil-structuring method. J. Amer. Oil Chem. Soc., 89: 749-780.

Doan, C D; Patel, A R; Tavernier, I; De Clercq, N; Van Raemdonck, K; Van de Walle, D; Delbaere, C and
Dewettinck, K (2016). The feasibility of wax-based oleogel as a potential co-structurant with palm oil in low-saturated fat confectionery fillings. Eur. J. Lipid Sci. Technol., 118: 1903-1914.

Doan, C D; Tavernier, I; Okuro, P K and Dewettinck, K (2018). Internal and external factors affecting the crystallization, gelation and applicability of waxbased oleogels in food industry. Innov. Food Sci. Emerg. Technol., 45: 42-52.

Doan, C D; To, C M; De Vrieze, M; Lynen, F; Danthine, S; Brown, A; Dewettinck, K and Patel, A R (2017). Chemical profiling of the major components in natural waxes to elucidate their role in liquid oil structuring. Food Chem., 214: 717-725.

Doan, C D; Van de Walle, D; Dewettinck, K and Patel, A R (2015). Evaluating the oil-gelling properties of natural waxes in rice bran oil: Rheological, thermal and microstructural study. J. Amer. Oil Chem. Soc., 92: 801-811.

El-Hadad, N N M; Youssef, M M; Abd El-Aal, M $\mathrm{H}$ and Abou-Gharbia, H H (2011). Utilisation of red palm olein in formulating functional chocolate spread. Food Chem., 124: 285-290.

El-Kalyoubi, M; Khallaf, M F; Abdelrashid, A and Mostafa, E M (2011). Quality characteristics of chocolate - Containing some fat replacer. Ann. Agric. Sci., 56: 89-96.

Endlein, E and Peleikis, K H (2011). Natural waxes Properties, composition and applications. SOFW J., 137: 1-8.

Gold, I L; Ukhun, M E and Akoh, C C (2011). Characteristics of eutectic compositions of restructured palm oil olein, palm kernel oil and their mixtures. J. Amer. Oil Chem. Soc., 88: 1659-1667.

Hwang, H S; Kim, S; Evans, K O; Koga, C and Lee, Y (2015). Morphology and networks of sunflower wax crystals in soybean oil organogel. Food Struct., 5: 10-20.

Jeyarani, T; Banerjee, T; Ravi, R and Gopala Krishna, A G (2013). Omega-3 fatty acids enriched chocolate spreads using soybean and coconut oils. J. Food Sci. Technol., 52: 1082-1088.

Jung, D; Oh, I; Lee, J and Lee, S (2020). Utilization of butter and oleogel blends in sweet pan bread for saturated fat reduction: Dough rheology and baking performance. $L W T, 125: 109194$.

Kim, J Y; Lim, J; Lee, J H; Hwang, H S and Lee, S (2017). Utilization of oleogels as a replacement for 
solid fat in aerated baked goods: Physicochemical, rheological, and tomographic characterization. J. Food Sci., 82: 445-452.

Kushairi, A; Loh, S K; Azman, I; Elina, H; Meilina, O-A; Zanal Bidin, M N I; Razmah, G; Shamala, $S$ and Ghulam, K A P (2018). Oil palm economic performance in Malaysia and R\&D progress in 2017. J. Oil Palm Res., 30: 163-195.

Lim, J; Hwang, H S and Lee, S (2017). Oil-structuring characterization of natural waxes in canola oil oleogels: Rheological, thermal, and oxidative properties. Appl. Biol. Chem., 60: 17-22.

Manzocco, L; Valoppi, F; Calligaris, S; Andreatta, F; Spilimbergo, S and Nicoli, M C (2017). Exploitation of k-carrageenan aerogels as template for edible oleogel preparation. Food Hydrocoll., 71: 68-75.

Marangoni, A and Garti, N (2011). Edible Oleogels: Structure and Health Implications. Second edition. AOCS Press, Urbana, USA.

Mert, B and Demirkesen, I (2016). Reducing saturated fat with oleogel/shortening blends in a baked product. Food Chem., 199: 809-816.

Mohd Razalli, N H; Chin, N L; Yusof, Y A and Mahyudin, N (2016). Quality changes of stabilizerfree natural peanut butter during storage. J. Food Sci. Technol., 53: 694-702.

MPOB (2017). Palm olein. Pocketbook of Oil Palm Uses. Sixth edition. MPOB, Bangi. 17 pp.

Mwangi, W W; Ho, K W; Tey, B T and Chan, E $S$ (2016). Effects of environmental factors on the physical stability of Pickering-emulsions stabilized by chitosan particles. Food Hydrocoll., 60: 543-550.

Patel, A R and Dewettinck, K (2016). Edible oil structuring: An overview and recent updates. Food Funct., 7: 20-29.

Patel, A R; Rajarethinem, P S; Grędowska, A; Turhan, O; Lesaffer, A; De Vos, W H; Van de Walle, D and Dewettinck, K (2014). Edible applications of shellac oleogels: Spreads, chocolate paste and cakes. Food Funct., 5: 645-652.

Patel, A R; Schatteman, D; De Vos, W H; Lesaffer, A and Dewettinck, K (2013). Preparation and rheological characterization of shellac oleogels and oleogel-based emulsions. J. Colloid Interface Sci., 411: 114-121.

Prasanth Kumar, P K P; Jeyarani, T and Gopala Krishna, A G G (2016). Physicochemical characteristics of phytonutrient retained red palm olein and butter-fat blends and its utilization for formulating CS. J. Food Sci. Technol., 53: 3060-3072.

Pușcaș, A; Mureșan, V; Socaciu, C and Muste, S (2020). Oleogels in food: A review of current and potential applications. Foods, 9: 70.

Rocha, J C B; Lopes, J D; Mascarenhas, M C N; Arellano, D B; Guerreiro, L M R and da Cunha, R $L$ (2013). Thermal and rheological properties of organogels formed by sugarcane or candelilla wax in soybean oil. Food Res. Int., 50: 318-323.

Roe, M; Pinchen, H; Church, S; Elahi, S; Walker, M; Farron-Wilson, M; Buttriss, J and Finglas, P (2013). Trans fatty acids in a range of UK processed foods. Food Chem., 140: 427-431.

Samsudin, S Y (2006). Low-fat chocolate spread based on palm oil. Palm Oil Developments, 45: 27-30.

Saw, M H; Lim, W H; Badlishah, S B and Tan, C P (2020). Screening of organogelators for structuring palm superolein. J. Oil Palm Res., 32: 152-158.

Shamsudin, S Y (2004). Trans free palm based chocolate spread. MPOB Information Series No. 251.

Shamsudin, S Y; Abd Hamid, R and Kanagaratnam, $S$ (2015). Chocolate spread with tocotrienol. $M P O B$ Information Series No. 584.

Wendt, A; Abraham, K; Wernecke, C; Pfeiffer, J and Flöter, E (2017). Application of $\beta$-sitosterol $+\gamma$-oryzanol-structured organogel as migration barrier in filled chocolate products. J. Amer. Oil Chem. Soc., 94: 1131-1140.

Wolfer, T L; Acevedo, N C; Prusa, K J; Sebranek, J G and Tarté, R (2018). Replacement of pork fat in frankfurter-type sausages by soybean oil oleogels structured with rice bran wax. Meat Sci., 145: 352362.

Yi, B R; Kim, M J; Lee, S Y and Lee, J H (2017). Physicochemical properties and oxidative stability of oleogels made of carnauba wax with canola oil or beeswax with grapeseed oil. Food Sci. Biotechnol., 26: 79-87.

Yilmaz, E and Öğütcü, M (2013). The texture, sensory properties and stability of cookies prepared with wax oleogels. Food Funct., 6: 1194-1204.

Yuping, S H I; Baomin, L and Richard, H (2005). Crystal morphology, microstructure, and textural properties of model lipid systems. J. Amer. Oil Chem. Soc., 82: 399-408. 